\title{
Short-term consumption of a high-sucrose diet has a pro-oxidant effect in rats
}

\author{
Jérôme Busserolles, Edmond Rock, Elyett Gueux, Andrzej Mazur, Pascal Grolier and Yves Rayssiguier* \\ Centre de Recherche en Nutrition Humaine d'Auvergne, Unité des Maladies Métaboliques et Micronutriments, INRA, Theix, \\ 63122 Saint-Genès-Champanelle, France
}

(Received 14 May 2001 - Revised 12 November 2001 - Accepted 14 December 2001)

\begin{abstract}
The underlying mechanisms for the detrimental consequences of a high-fructose diet in animal models are not clear. However, the possibility exists that fructose feeding facilitates oxidative damage. Thus, the aim of the present study was to assess, in weaning rats, the effect of a highsucrose diet $v$. starch diet for 2 weeks on oxidative stress variables. Plasma lipid levels were measured and lipid peroxidation was evaluated by urine and plasma thiobarbituric acid-reactive substances (TBARS). The susceptibilities of several tissues to peroxidation were determined in tissue homogenates after in vitro lipid peroxidation. Antioxidant defence variables were evaluated by measuring plasma and heart vitamin E levels, and heart superoxide dismutase (SOD) and glutathione peroxidase (GPX) activities. Higher plasma triacylglycerol $(P<0 \cdot 01)$ and TBARS $(P<0 \cdot 01)$ levels were found in rats fed the sucrose diet as compared with the starch-fed group, whereas plasma $\alpha$-tocopherol levels were significantly decreased in the sucrose-fed group compared with the starch-fed group $(P<0 \cdot 01)$. Higher urine TBARS $(P<0 \cdot 01)$ were found in the sucrose-fed group compared with the starch-fed group, suggesting increased production of these substances from lipid peroxidation in vivo. Higher susceptibility to peroxidation in heart, thymus and pancreas was also found in the sucrose-fed group $v$. the starch-fed group. No statistical differences were observed for liver TBARS level between the two groups. Heart SOD activity was significantly decreased $(P<0 \cdot 001)$ in the sucrose-fed group compared with the starch-fed group, whereas heart vitamin E level and GPX activity were not different between the groups. However, the in vitro generation of superoxide radical in heart homogenate, measured by electron spin resonance detection and spin trapping, was not increased in the sucrose-fed group compared with starch-fed rats. Altogether, the results indicate that a short-term consumption of a high-sucrose diet negatively affects the balance of free radical production and antioxidant defence in rats, leading to increased lipid susceptibility to peroxidation.
\end{abstract}

High-sucrose diet: Oxidative stress: Free radicals: Rats

D-Fructose is a sugar that exists in foods as a simple sugar and as a component of the disaccharide sucrose, consisting of one molecule of glucose and one of fructose. Because of the use of high-fructose corn sweeteners and of sucrose in manufactured foods, the dietary consumption of fructose has increased several-fold from that present in natural foods (Henry et al. 1991). Although there is little evidence that modest amounts of fructose have detrimental effects on carbohydrate and lipid metabolism, larger doses of fructose have been associated with numerous metabolic abnormalities in human subjects and laboratory animals, suggesting that high-fructose consumption induces adverse effects on health (Hallfrisch, 1990; Henry et al. 1991). High-sucrose and high-fructose diets were used in animal models to induce the metabolic changes observed in syndrome $\mathrm{X}$, a disorder in which insulin resistance, hypertension, dyslipidaemia and high incidence of cardiovascular diseases are described (Reaven, 1988). The underlying mechanisms for the detrimental consequences of a highfructose diet in animal models are not clear. However, the possibility exists that fructose feeding facilitates oxidative damage (McDonald, 1995). The hypothesis is supported by previous findings showing that fructose has a deleterious effect both when antioxidant defences are

\footnotetext{
Abbreviations: DMSO, dimethylsulfoxide; GPX, glutathione peroxidase; PBN, phenyl N-tert-butylnitrone; SOD, superoxide dismutase; TBARS, thiobarbituric acid-reactive substances.

* Corresponding author: Dr Y. Rayssiguier, fax +33 4736246 38, email yves.rayssiguier@clermont.inra.fr
} 
decreased or when free-radical production is increased. It is well known that inadequate antioxidant protection is a consequence of $\mathrm{Cu}$ deficiency due to a reduction of superoxide dismutase (SOD) activity and increased lipid peroxidation is a contributing factor in the pathophysiology of low-Cu status (Rayssiguier et al. 1993). In Cu-deficient rats, the consumption of sucrose or fructose as the carbohydrate source causes severe pathology and mortality. In contrast, the consumption of starch does not produce such pathology and $\mathrm{Cu}$-deficient animals survive (Fields et al. 1984). Increased oxidative stress occurs in $\mathrm{Mg}$-deficient rats due to inflammation (Malpuech-Brugère et al. 2000) and sucrose has been shown to be an aggravating factor as compared with starch (Rayssiguier et al. 1981). The role of oxidative stress has also been suggested since a free-radical scavenger such as vitamin E improves insulin sensivity in high-fructose-fed rats (Faure et al.1997). Although oxidative stress has been suggested as one mechanism for detrimental effects of fructose (McDonald, 1995), corroborating measures of lipid peroxidation are lacking. Altogether in these experiments, the possibility exists that a high-fructose diet has a pro-oxidant effect in rats and that the detrimental effect of a high-sucrose diet may be attributed to its content of fructose. Thus, the aim of the present study was to assess in weaning rats the effect of a high-sucrose diet $v$. starch diet on oxidative stress variables. The consequence of sucrose feeding in rats was assessed by measuring several variables related to oxidative stress in blood, urine and tissues.

\section{Materials and methods}

\section{Experimental design}

Weaning male Wistar rats (IFFA-CREDO, L'Arbresle, France), 3 weeks old, weighing 61 (SEM 2) g were randomly divided into starch or sucrose groups (sixteen per group). The Institution's guidelines for the care and use of laboratory animals were followed. Rats were housed in wired-bottomed cages in a temperature-controlled room $\left(22^{\circ} \mathrm{C}\right)$ with a $12 \mathrm{~h}$ light-dark cycle and they were fed the appropriate diets for 2 weeks. Diet and distilled water were provided ad libitum. The synthetic diets contained $(\mathrm{g} / \mathrm{kg})$ : casein 200 , starch or sucrose 650 , corn oil 50, alphacel 50, DL-methionine 3, choline bitartrate 2, AIN-76 mineral mix 35, AIN-76 A vitamin mix 10 (ICN Biomedicals, Orsay, France).

\section{Sample collections}

Eight rats from each group were held individually in stainless-steel metabolic cages and had access to water and food ad libitum for $4 \mathrm{~d}$ before killing. The urine samples were collected (for $24 \mathrm{~h}$ before killing) into $50 \mathrm{ml}$ graduated tubes attached to urine collection funnels with screens to prevent contamination from faeces. Urine volumes were accurately measured and the samples were centrifuged and stored at $-80^{\circ} \mathrm{C}$ until analysis. Non-fasted rats were weighed, anaesthetised with sodium pentobarbital $(40 \mathrm{mg} /$ $\mathrm{kg}$ body weight, intraperitoneally) and killed. Blood was collected from the abdominal aorta into heparinised tubes. Plasma samples obtained after low-speed centrifugation $(2000 \mathrm{~g}, 15 \mathrm{~min})$ were stored at $-80^{\circ} \mathrm{C}$ for biochemical analysis. The heart, liver, pancreas and thymus were rapidly removed, washed in ice-cold saline $(9 \mathrm{~g}$ $\mathrm{NaCl} / \mathrm{l}$ ), placed in liquid $\mathrm{N}_{2}$ and stored at $-80^{\circ} \mathrm{C}$ before performing the lipid peroxidation assay. The remaining rats ( $n 8$ per group) from each group were used for the spin trapping experiment.

\section{Plasma and urine analysis}

Plasma thiobarbituric acid-reactive substances (TBARS) levels were determined by spectrofluorometry (LS 5; Perkin Elmer, Norwalk, CT, USA) as previously described (Rayssiguier et al. 1993). The levels of TBARS in urine samples were measured as previously described (Lee et al. 1992) and calculated on the basis of $24 \mathrm{~h}$ urine volume. Plasma vitamin E was assayed by reversedphase HPLC (Kontron serie 400; Kontron, St Quentin en Yvelines, France) using a hexane extract. Briefly, $\alpha$-tocopherol acetate (Sigma, Saint Quentin Fallavier, France) was added to samples as an internal standard, then they were extracted twice with hexane, after ethanol precipitation of the proteins. This extract was evaporated to dryness under $\mathrm{N}_{2}$, dissolved in ethanol-methylene chloride $(65: 35, \mathrm{v} / \mathrm{v})$ and injected onto a $\mathrm{C}_{18}$ column (Interchim, Montluçon, France) (Nucleosil; $250 \mathrm{~mm}$ long, i.d. $46 \mathrm{~mm}$, $5 \mu \mathrm{m}$ particles). Pure methanol, at a flow rate of $2 \mathrm{ml} / \mathrm{min}$ eluted $\alpha$-tocopherol in $5.0 \mathrm{~min}$ and tocopherol acetate in $6.3 \mathrm{~min}$. The compounds were detected by u.v. (292 nm) spectrometry then quantified by internal and external calibration using daily-controlled standard solutions. Triacylglycerol (Biotrol, Paris, France) and cholesterol (Biomerieux, Charbonnière les Bains, France) were determined in plasma by enzymatic procedures. $\mathrm{Cu}$ and $\mathrm{Zn}$ contents in plasma were determined by flame atomic absorption spectrometry (Perkin-Elmer series 800; Perkin Elmer).

\section{Tissue susceptibility to peroxidation}

The susceptibilities of heart, liver, thymus and pancreas to peroxidation were determined in tissue homogenates after lipid peroxidation was induced with $2 \mu \mathrm{M}-\mathrm{FeSO}_{4}-$ $50 \mu \mathrm{M}$-ascorbate for $30 \mathrm{~min}$ in a water bath at $37^{\circ} \mathrm{C}$, using a standard of 1,1,3,3-tetraethoxypropane, as previously described (Rayssiguier et al. 1993).

\section{Heart superoxide dismutase, glutathione peroxidase activities and vitamin $E$ level}

Heart homogenates were used for SOD and glutathione peroxidase (GPX) determination. Tissue SOD activity was determined using Ransod kit from Randox (Randox Laboratories, Crumlin, N. Ireland, UK). Tissue GPX activity was determined by the modified method of Paglia \& Valentine (1967) using tert-butyl hydroperoxide as substrate. The results were expressed as U/mg protein for both SOD and GPX activities. Protein content was determined by bicinchoninic acid protein assay kit (Pierce, Rockford, IL, USA) using bovine serum albumin 
as the standard. Tissue vitamin E level was determined with the same procedure as described for plasma vitamin E determination, after heart homogenisation in Triton $1 \mathrm{X}$.

\section{Spin trapping experiment}

To investigate free radical production, heart homogenates were incubated at $37^{\circ} \mathrm{C}$ with phenyl $N$-tert-butylnitrone (PBN) as the spin trap in the presence of dimethylsulfoxide (DMSO). Hearts were homogenised in $10 \mathrm{ml}$ $20 \mathrm{mM}-\mathrm{HEPES}-150 \mathrm{mM}-\mathrm{KCl}$ buffer $(\mathrm{pH} 7 \cdot 2) / \mathrm{g}$, and then centrifuged at $10000 \mathrm{~g}$ for $7 \mathrm{~min}$. To $150 \mu \mathrm{l}$ homogenate was added $25 \mu \mathrm{l} 2 \mathrm{M}-\mathrm{PBN}$ in DMSO, leading to a final concentration of $333 \mathrm{~mm}-\mathrm{PBN}$. Buffer $(25 \mu \mathrm{l})$ and $6.47 \mathrm{M}-\mathrm{FeSO}_{4}(5 \mu \mathrm{l})$ were added at room temperature and used immediately as previously described (Rock et al. 1995). Three capillaries of $20 \mu \mathrm{l}$ were filled with the sample and transferred into a quartz tube. The electron spin resonance spectra was recorded at room temperature using an electron spin resonance spectrometer (Brucker ECS 106, Brucker, Karlsruhe, Germany) operating at $9.79 \mathrm{GHz}$ with the following conditions: microwave power $20 \mathrm{~mW}$; modulation frequency $10 \mathrm{KHz}$; modulation amplitude $1.016 \times 10^{-4} \mathrm{~T}$; time constant $61.92 \mathrm{~ms}$; receiver gain $5 \times 10^{5}$. The three line spectrum obtained with the samples was subtracted from a basal spectrum obtained with capillaries containing heart homogenate without $\mathrm{FeSO}_{4}$.

\section{Statistical analysis}

Statistical analysis was performed using GraphPad InStat (GraphPad Inc., San Diego, CA, USA) software package. Results were expressed as mean values with their standard errors. The statistical significance of differences between means were assessed by Student's $t$ test. Differences were considered statistically significant at $P<0.05$

\section{Results}

The sucrose-enriched diet did not affect the normal growth of the rats. The mean body weight was 156 (SEM 2) $g$ for the starch group and 154 (SEM 3) g for the sucrose group respectively. Plasma triacylglycerol levels were significantly greater in the sucrose group compared with the starch group $(P<0.01)$ whereas total plasma cholesterol levels were not significantly different between the two experimental groups. Plasma $\alpha$-tocopherol levels were significantly lower in the sucrose group compared with the starch group $(P<0 \cdot 01)$. The $\alpha$-tocopherol:triacylglycerol ratio was significantly decreased in the sucrose group as compared with the control group $(P<0.001)$ (Table 1$)$.

Higher plasma and urine TBARS $(P<0.01)$ were found in the sucrose group compared with the starch group (Table 2). After exposure of tissue homogenates to $\mathrm{Fe}$ induced lipid peroxidation, TBARS were significantly higher in heart $(P<0 \cdot 01)$, thymus $(P<0 \cdot 001)$ and pancreas $(P<0.01)$ from the sucrose group compared with the starch group (Table 3 ). No statistical differences were observed for liver TBARS levels between the two groups.

The vitamin E levels in the heart homogenates were not
Table 1. Plasma triacylglycerol, cholesterol and vitamin E concentrations and plasma vitamin E:triacylglycerol ratios in rats consuming a starch- or sucrose-based diet†

(Mean values with their standard errors for eight rats per group)

\begin{tabular}{|c|c|c|c|c|}
\hline \multirow[t]{2}{*}{ Diet... } & \multicolumn{2}{|c|}{ Starch-based } & \multicolumn{2}{|c|}{$\begin{array}{c}\text { Sucrose- } \\
\text { based }\end{array}$} \\
\hline & Mean & SEM & Mean & SEM \\
\hline Triacylglycerol $(\mathrm{mmol} / \mathrm{l})$ & 0.73 & $0 \cdot 12$ & $1.63^{* *}$ & 0.20 \\
\hline Cholesterol $(\mathrm{mmol} / \mathrm{l})$ & 2.04 & 0.07 & 1.84 & 0.08 \\
\hline Vitamin $E(\mu \mathrm{g} / \mathrm{ml})$ & 9.92 & 0.71 & $7 \cdot 06^{\star \star}$ & 0.62 \\
\hline Vitamin E:triacylglycerol $(\mu \mathrm{g} / \mathrm{mol})$ & 8.49 & 0.57 & $3.95^{\star \star \star}$ & 0.78 \\
\hline
\end{tabular}

†For details of diets and procedures, see pp. 338-339.

Mean values were significantly different from those of the starch-based group: ${ }^{\star \star} P<0.01,{ }^{\star \star \star} P<0.001$

significantly different between the starch and sucrose groups. Heart SOD activity was significantly decreased $(P<0.001)$ in the sucrose group compared with the starch group (Table 4), whereas heart GPX level was not different between the groups. Plasma $\mathrm{Cu}$ was significantly lower $(P<0.001)$ and plasma $\mathrm{Zn}$ higher $(P<0.01)$ in the sucrose group than in the starch group.

The characteristic electron spin resonance spectra obtained from the incubation of heart homogenates with PBN in the presence of DMSO are shown in Fig. 1. The hyperfine coupling constants for this signal $\left(\mathrm{a}^{\mathrm{N}}=16.34 \times 10^{-4} \quad\left(\mathrm{SEM} \quad 0.03 \times 10^{-4}\right) \quad \mathrm{T}\right.$ and $\quad\left(\mathrm{a}^{\mathrm{H}}=\right.$ $3.61 \times 10^{-4}\left(\right.$ SEM $\left.0.02 \times 10^{-4}\right) \mathrm{T}$ are close to those determined for the $\mathrm{PBN} \cdot \mathrm{CH}_{3}$ adduct detected under similar conditions (Burkitt \& Mason, 1991). When heart homogenates were incubated with $200 \mu \mathrm{M}-\mathrm{FeSO}_{4}$, higher signal intensities were observed. We used these conditions to determine the kinetics of the reaction by following the intensity of the first line of the second doublet (results not shown). After $60 \mathrm{~min}$ incubation, for which a higher signal intensity was reached, we observed no difference in the amount of the spin adducts produced in homogenates from sucrose v. starch-fed rats.

\section{Discussion}

The level of the peroxidation marker (TBARS) significantly increased in plasma from rats fed the sucrose diet as compared with the starch group. In addition, sucrose feeding is accompanied by hypertriacylglycerolaemia and

Table 2. Plasma and urine thiobarbituric acid-reactive substance values in rats consuming a starch- or sucrose-based diet $†$ (Mean values with their standard errors eight rats per group)

\begin{tabular}{llllll}
\hline Diet... & \multicolumn{2}{c}{ Starch-based } & & \multicolumn{2}{c}{ Sucrose-based } \\
\cline { 2 - 3 } & Mean & SEM & & Mean & SEM \\
\hline Plasma TBARS $(\mathrm{nmol} / \mathrm{ml})$ & 1.97 & 0.04 & & $2.17^{\star *}$ & 0.05 \\
Urine TBARS $(\mathrm{nmol} / 24 \mathrm{~h})$ & 0.57 & 0.10 & & $1.29^{\star *}$ & 0.20 \\
\hline
\end{tabular}

TBARS, thiobarbituric acid-reactive substances.

†For details of diets and procedures, see pp. 338-339.

Mean values were significantly different from those of the starch-based groups ${ }^{* *} P<0.01$. 
Table 3. Susceptibility of tissues to peroxidation in rats consuming a starch- or sucrose-based diet†

(Mean values with their standard errors for eight rats per group)

\begin{tabular}{|c|c|c|c|c|}
\hline \multirow[t]{2}{*}{ Diet... } & \multicolumn{2}{|c|}{$\begin{array}{l}\text { Starch- } \\
\text { based }\end{array}$} & \multicolumn{2}{|c|}{$\begin{array}{l}\text { Sucrose- } \\
\text { based }\end{array}$} \\
\hline & Mean & SEM & Mean & SEM \\
\hline Heart TBARS $(\mathrm{nmol} / \mathrm{g}$ wet $\mathrm{wt}) \ddagger$ & 94 & 10 & $152^{\star *}$ & 11 \\
\hline Liver TBARS (nmol/g wet wt)‡ & 117 & 11 & 142 & 20 \\
\hline Thymus TBARS (nmol/g wet wt) $\ddagger$ & 40 & 8 & $104^{\star \star \star}$ & 12 \\
\hline Pancreas TBARS (nmol/g wet wt) $\ddagger$ & 28 & 4 & $53^{\star \star}$ & 7 \\
\hline
\end{tabular}

TBARS, thiobarbituric acid-reactive substances.

†For details of diets and procedures, see pp. 338-339.

†TBARS were measured in tissue homogenates after lipid peroxidation induced with $\mathrm{FeSO}_{4}$-ascorbate for $30 \mathrm{~min}$ at $37^{\circ} \mathrm{C}$ (for details, see p. 339). Mean values were significantly different from those of the starch-based group: ${ }^{\star \star} P<0.01,{ }^{\star \star \star} P<0.001$.

plasma contains many substances that react in the thiobarbituric assay. Thus the value of malondialdehyde in plasma as an indicator for lipid peroxidation is limited (Rice-Evans et al. 1991). However, we also found a significant decrease in vitamin E plasma level. Since vitamin E normally acts as an antioxidant, low vitamin E level probably is the result of increased vitamin $\mathrm{E}$ utilisation (Esterbauer et al. 1992). Both sucrose and fructose given at abnormally high amount in the diet have been shown to increase plasma triacylglycerol concentration (Vrana \& Fabry, 1983; Mamo et al. 1991; Frayn \& Kingman, 1995). Unlike other fat-soluble vitamins, vitamin $\mathrm{E}$ has no specific transport protein, but rather is transported in plasma lipoproteins and tocopherol is secreted in the liver in VLDL and protects lipoproteins by preventing oxidation. When lipoproteins are depleted of antioxidants, unsaturated fatty acids are rapidly oxidised and the vitamin E depletion in sucrose-fed rats may predispose lipoproteins to subsequent oxidative stress (Esterbauer et al. 1992). Thus, an increase in triacylglycerol-rich lipoprotein and increased lipoprotein susceptibility to peroxidation are factors that

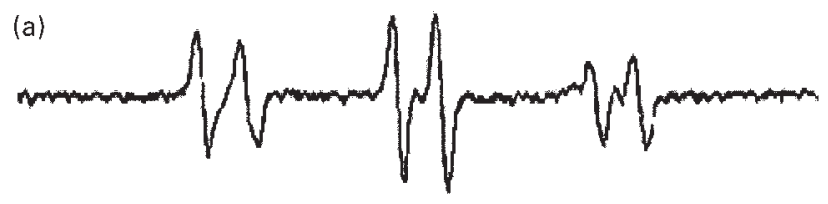

(b)
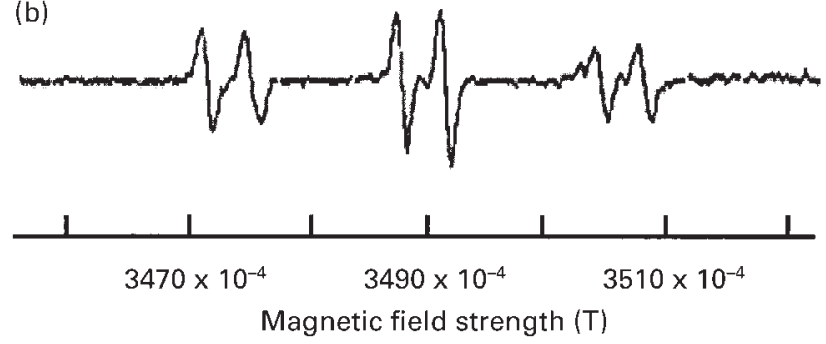

Fig. 1. Electron spin resonance spectra from (a) starch and (b) sucrose rats. Typical electron spin resonance spectra of heart homogenates with the spin-trapping agent phenyl $\mathrm{N}$-tert-butylnitrone. The spectra for starch (a) and sucrose (b) rats were obtained at room temperature under the conditions described on p. 339. For details of diets and procedures, see pp. 338-339.
Table 4. Superoxide dismutase and glutathione peroxidase activities and vitamin E levels in heart, and plasma copper and zinc levels in rats consuming a starch- or sucrose-based diet†

(Mean values with their standard errors for eight rats per group)

\begin{tabular}{|c|c|c|c|c|}
\hline \multirow{2}{*}{ Diet... } & \multicolumn{2}{|c|}{ Starch-based } & \multicolumn{2}{|c|}{ Sucrose-based } \\
\hline & Mean & SEM & Mean & SEM \\
\hline Vitamin $E(\mu \mathrm{g} / \mathrm{g}$ wet wt) & 28.72 & 0.91 & $26 \cdot 45$ & 0.97 \\
\hline SOD (U/mg protein) & 39.89 & 2.08 & $29 \cdot 75^{\star \star \star}$ & 0.91 \\
\hline GPX (U/mg protein) & $52 \cdot 10$ & 4.02 & 55.43 & $5 \cdot 60$ \\
\hline $\mathrm{Cu}(\mathrm{mg} / \mathrm{l})$ & 0.74 & 0.04 & $0.23^{\star \star \star}$ & 0.07 \\
\hline $\mathrm{Zn}(\mathrm{mg} / \mathrm{l})$ & $1 \cdot 21$ & 0.01 & $1.42^{\star \star}$ & 0.05 \\
\hline
\end{tabular}

SOD, superoxide dismutase; GPX, glutathione peroxidase.

†For details of diets and procedures, see pp. 338-339.

Mean values were significantly different from those of the starch-based group: ${ }^{\star *} P<0.01,{ }^{* \star *} P<0.001$.

may combine to contribute to an increased risk for cardiovascular diseases (Ross, 1999). Accordingly, compared with starch, fructose feeding results in higher occurrence of aortic atherosclerotic plaque in animal models as shown previously (Kritchevsky et al.1980).

Sucrose feeding in rats is accompanied by a significant increase in the urinary excretion of TBARS suggesting increased production of these substances from lipid peroxidation in vivo. Several reports have indicated that a positive relationship exists between in vivo peroxidation and urinary malondialdehyde levels (Brooks \& Klamert, 1968). For instance, vitamin E-deficient rats excrete higher levels of TBARS in urine compared with vitamin E-supplemented rats (Draper et al. 1984). This demonstrates that total urinary TBARS level corresponds to the increase in vivo lipid peroxidation associated with vitamin E deficiency (Lee et al. 1992). Moreover, the present experiment clearly indicates that heart, thymus and pancreas are more susceptible to in vitro peroxidation. Unlike other organs, liver susceptibility to peroxidation was not significantly increased in rats fed a high-fructose diet, suggesting a greater protection against oxidative stress in this organ. Comparing diets containing a large percentage of energy provided by sucrose results in a general decline of glucose homeostasis and an increased risk for the development of non-insulin-dependant diabetes mellitus (Reiser, 1982). In general, the development of type 2 diabetes is associated with pancreatic $\beta$-cell dysfunction occurring together with insulin resistance. The present experiments suggest that sucrose feeding can cause severe cell injury to $\beta$ cells as shown by increase susceptibility of pancreas to oxidative damage. Pancreatic $\beta$ cells have a much lower scavenging capacity than most other tissues and they are unable to adapt their antioxidant enzyme expression in response to chronic oxidative stress (Tiedge et al. 1997). Oxidative free radicals may in the first instance stimulate the growth of pancreatic $\beta$ cells and then, the ongoing increased oxidative stress will progressively destroy pancreatic cells and result in insulin deficiency (Bakker et al. 2000). Moreover, there has been growing interest in the effects of antioxidants on insulin activity. $\alpha$-Tocopherol supplementation improves insulin action in patients with non-insulin-dependant diabetes mellitus (Paolisso et al. 1993) and in rats fed high a dosage of 
fructose (Faure et al. 1997). Of particular significance is the observation that hearts from fructose-fed rats are more susceptible to in vitro peroxidation as compared with the starch group. These results emphasise the potential detrimental effect of fructose on vascular risk (Halfrisch, 1990), as shown by hyperlipaemia, decreased lipoprotein protection and cardiovascular susceptibility to free radical-mediated injury. We also found that the high-sucrose diet may affect the balance of oxyradical production and antioxidant defence in the thymus; thus oxidative injury may occur in this tissue involved in host immune response.

The decreased heart SOD activity of rats fed the sucrose diet compared with starch-fed rats is accompanied by a large decrease in blood plasma $\mathrm{Cu}$ concentration. The interaction of dietary fructose with $\mathrm{Cu}$ has received considerable attention (Fields et al. 1984; O'Dell, 1993). The antagonism between $\mathrm{Zn}$ and $\mathrm{Cu}$ is well known (Van Campen \& Scaife, 1967). However, whether the increased plasma $\mathrm{Zn}$ concentration observed in rats fed the sucrose diet is the consequence of decreased $\mathrm{Cu}$ status is unclear. Finally, the possibility exists that $\mathrm{Cu}$ depletion results in reduced activity of the $\mathrm{Cu}$-containing enzyme SOD. However, in previous experiments, the SOD activity of red blood cells was also found to be lower in rats fed a highfructose diet although the plasma $\mathrm{Cu}$ was not different in the starch group (Faure et al. 1997) and vitamin E supplementation was accompanied by a normalisation of red blood cell SOD activity. Thus, the hypothesis that the protein could be damaged by oxidative stress has been advanced (Faure et al. 1997). Whatever the mechanisms involved, SOD depletion might participate in cardiac vulnerability to oxidative stress since this antioxidant enzyme has a key role in the cell protection against the deleterious effects of the superoxide anion (Halliwell, 1996). GPX is also important in the protection of the cell from oxygen radical toxicity. In contrast to the SOD activity, the GPX activity was not modified in heart homogenates from the sucrose group as compared with the starch group, suggesting that there is no depletion of this antioxidant enzyme or that a feed-back mechanism results in a restoration to normal enzyme level. Moreover, whereas plasma vitamin E level was lower in the sucrose group, heart vitamin E levels were not different between groups.

Heart SOD activity being decreased, the possible consequent decreased dismutation of the superoxide radical $\mathrm{O}_{2}^{-}$. could result in an increased superoxide radical availability in this organ. Hence, we tested if the in vitro generation of the superoxide radical is affected differently in heart homogenates from sucrose- or starch-fed rats. We used electron spin resonance spectroscopy to study the production of free radicals in heart homogenates. As previously shown, in the presence of PBN and DMSO, primary free radical $\left(\mathrm{O}_{2}^{-}\right.$; $\cdot \mathrm{OH})$ rather than lipid-derived secondary radicals (R., RO·) were generated (Rock et al.1995). Surprisingly, electron spin resonance spectra indicate that primary free radical species $\left(\mathrm{O}_{2}^{-}, \cdot \mathrm{OH}\right)$ were not increased in the sucrose group compared with starch-fed rats. However, these results from in vitro incubation of heart homogenates does not exclude a possible in vivo greater primary free radical production induced by a high-fructose consumption.
There are several possible pathways by which a diet rich in sucrose may alter cellular metabolism, which in turn may accelerate oxidative stress. The increased oxidative stress could be due to oxygen free radical production and/or decreased protection by non-enzymatic or enzymatic antioxidants (Halliwell, 1996). Moreover, the susceptibility of tissue to oxidative stress can be dependent on alteration in lipid composition. Another possibility is that sucrose feeding induces accumulation of advanced glycation products and that oxidative degradation of glucose or fructose adducts leads to production of free radicals (Levi \& Werman, 1998). Thus, further research is needed to define the interactions among fructose, glycation and oxidative stress more clearly. Which of these possible pathways of free-radical generation occur in response to a highfructose diet was not addressed in our present study.

In conclusion, the present study presents the evidence that short-term consumption of a high-sucrose diet negatively affects the balance of oxyradical production and antioxidant defence, suggesting that metabolic abnormalities in human subjects and laboratory animals associated with high-fructose consumption can be related to oxidative stress. Special attention should be made to the potential consequences of increased consumption of fructose combined with low dietary intake of antioxidant molecules (vitamins, minerals, phyto-micronutrients, etc.), particularly in relation to the development of cardiovascular diseases, non-insulin-dependant diabetes mellitus and the cluster of abnormalities designated as syndrome $\mathrm{X}$.

\section{Acknowledgements}

The authors would like to thank the expert technical assistance of C.Lab.

\section{References}

Bakker SJ, Ijzerman RG, Teerlink T, Westerhoff HV, Gans RO \& Heine RJ (2000) Cytosolic triglycerides and oxidative stress in central obesity: the missing link between excessive atherosclerosis, endothelial dysfunction, and beta-cell failure? Atherosclerosis 148, 17-21.

Brooks BR \& Klamerth OL (1968) Interaction of DNA with bifunctional aldehydes. European Journal of Biochemistry 5, $178-182$.

Burkitt MJ \& Mason RP (1991) Direct evidence for in vivo hydroxyl-radical generation in experimental iron overload: an ESR spin-trapping investigation. Proceedings of the National Academy of Sciences, USA 88, 8440-8444.

Draper HH, Polensek L, Hadley M \& McGirr LG (1984) Urinary malondialdehyde as an indicator of lipid peroxidation in the diet and in the tissues. Lipids 19, 836-843.

Esterbauer H, Gebicki J, Puhl H \& Jurgens G (1992) The role of lipid peroxidation and antioxidants in oxidative modification of LDL. Free Radical Biology and Medicine 13, 341-390.

Faure P, Rossini E, Lafond JL, Richard MJ, Favier A \& Halimi S (1997) Vitamin E improves the free radical defense system potential and insulin sensitivity of rats fed high fructose diets. Journal of Nutrition 127, 103-107.

Fields M, Ferretti RJ, Reiser S \& Smith JC (1984) The severity of copper deficiency in rats is determined by the type of dietary carbohydrates. Proceedings of the Society for Experimental Biology and Medicine 175, 530-537. 
Frayn KN \& Kingman SM (1995) Dietary sugars and lipid metabolism in humans. American Journal of Clinical Nutrition 62, 250S-263S.

Hallfrisch J (1990) Metabolic effects of dietary fructose. FASEB Journal 4, 2652-2660.

Halliwell B (1996) Oxidative stress, nutrition and health. Experimental strategies for optimization of nutritional antioxidant intake in humans. Free Radical Research 25, 57-74.

Henry RR, Crapo PA \& Thorburn AW (1991) Current issues in fructose metabolism. Annual Review of Nutrition 11, 21-39.

Kritchevsky D, Davidson LM, Kim HK, Krendel DA, Malhotra S, Mendelsohn D, van der Watt JJ, duPlessis JP \& Winter PA (1980) Influence of type of carbohydrate on atherosclerosis in baboons fed semi purified diets plus $0.1 \%$ cholesterol. American Journal of Clinical Nutrition 33, 1869-1887.

Lee HS, Shoeman DW \& Csallany AS (1992) Urinary response to in vivo lipid peroxidation induced by vitamin $\mathrm{E}$ deficiency. Lipids 27, 124-128.

Levi B \& Werman MJ (1998) Long-term fructose consumption accelerates glycation and several age-related variables in male rats. Journal of Nutrition 128, 1442-1449.

McDonald RB (1995) Influence of dietary sucrose on biological aging. American Journal of Clinical Nutrition 62, 284S-293S.

Malpuech-Brugère C, Nowacki W, Daveau M, Gueux E, Linard C, Rock E, Lebreton JP, Mazur A \& Rayssiguier Y (2000) Inflammatory response following acute magnesium deficiency in the rat. Biochimica et Biophysica Acta 1501, 91-98.

Mamo JC, Hirano T, James L, Szeto L \& Steiner G (1991) Partial characterization of the fructose-induced defect in very-lowdensity-lipoprotein triglyceride metabolism. Metabolism 40, $888-893$.

O’Dell BL (1993) Fructose and mineral metabolism. American Journal of Clinical Nutrition 58, 771S-778S.

Paglia DE \& Valentine WN (1967) Studies on the quantitative and qualitative characterization of erythrocyte glutathione peroxidase. Journal of Laboratory and Clinical Medicine 70, 158-169.
Paolisso G, D'Amore A, Giugliano D, Ceriello A, Varricchio M \& D'Onofrio F (1993) Pharmacologic doses of vitamin E improve insulin action in healthy subjects and non-insulindependent diabetic patients. American Journal of Clinical Nutrition 57, 650-656.

Rayssiguier Y, Gueux E, Bussière L \& Mazur A (1993) Copper deficiency increases the susceptibility of lipoproteins and tissues to peroxidation in rats. Journal of Nutrition 123, 1343-1348.

Rayssiguier Y, Gueux E \& Weiser D (1981) Effect of magnesium deficiency on lipid metabolism in rats fed a high carbohydrate diet. Journal of Nutrition 111, 1876-1883.

Reaven GM (1988) Banting lecture. Role of insulin resistance in human disease. Diabetes 37, 1595-1607.

Reiser S (1982) Metabolic risk factors associated with heart disease and diabetes in carbohydrate-sensitive humans when consuming sucrose as compared to starch. In Metabolic Effects of Utilisable Dietary Carbohydrates, pp. 239-259 [S Reiser, editor]. New York-Basel: Marcel Dekker, Inc.

Rice-Evans CA, Diplock AT \& Symons MCR [RH Burdon and $\mathrm{PH}$ van Knippenber, editors]. Amsterdam: Elsevier.

Rock E, Astier C, Lab C, Vignon X, Gueux E, Motta C \& Rayssiguier Y (1995) Dietary magnesium deficiency in rats enhances free radical production in skeletal muscle. Journal of Nutrition 125, 1205-1210.

Ross R (1999) Atherosclerosis: An inflammatory disease. New England Journal of Medicine 340, 115-126.

Tiedge M, Lortz S, Drinkgern J \& Lenzen S (1997) Relation between antioxidant enzyme gene expression and antioxidant defense status on insulin-producing cells. Diabetes $\mathbf{4 6}$, $1733-1742$.

Van Campen DR \& Scaife PU (1967) Zinc interference with copper absorption in rats. Journal of Nutrition 91, 473-476.

Vrana A \& Fabry P (1983) Metabolic effects of high sucrose or fructose intake. World Review of Nutrition and Dietetics 42 , $56-101$. 